\title{
Effects of silicon carbide contents on the microstructure of sintered steels
}

\author{
Wananurat Srijampan ${ }^{\mathrm{a}}$, Amporn Wiengmoon ${ }^{\mathrm{a}}$, Preeya Nakornkaew ${ }^{\mathrm{b}}$, Tapany Patcharawit ${ }^{\mathrm{b}}$, \\ Thanyaporn Yotkaew ${ }^{\mathrm{c}}$, Nattaya Tosangthum ${ }^{\mathrm{c}}$, Ruangdaj Tongsric ${ }^{\mathrm{c}, *}$ \\ a Department of Physics, Faculty of Science, Naresuan University, Phitsanulok 65000 Thailand \\ b School of Metallurgical Engineering, Institute of Engineering, Suranaree University of Technology, \\ Nakhon Ratchasima 30000 Thailand \\ c Particulate Materials Processing Technology (PMPT) Laboratory, Thailand National Metal and Materials \\ Technology Center, Pathum Thani 12120 Thailand
}

*Corresponding author, e-mail: ruangdt@mtec.or.th

Received 11 Nov 2020

Accepted 16 Apr 2021

\begin{abstract}
Silicon and carbon are common alloying elements in wrought steel production. A judicious content of silicon can prevent carbide precipitation. So silicon is commonly used in the production of carbide-free bainitic steel, which is one of advanced high strength steels. It was found previously that both silicon and carbon elements from silicon carbide additives can be alloyed to form iron-based powder compacts via sintering process. In this study, sintered steels were produced from mixtures of pre-alloyed Fe-0.50Mo-0.15Mn powder and various silicon carbide contents (1.0, 2.0, 3.0, and 4.0 wt.\%) using 'press and sinter' process. Microstructures of sintered steels changed in accordance with added silicon carbide content. The microstructure consisting of ferrite plate and martensite/austenite constituent in the low silicon carbide-added steel was changed to the microstructure with martensite matrix in high silicon carbideadded steel. Surprisingly, diffusional phase transformations resulting in the formations of pearlite and inverse bainite were occurred prior to diffusionless martensitic transformation in high silicon carbide-added steel. The ultimate tensile strength and hardness of the studied sintered steels increased with increasing martensite volume fraction but dropped with the presence of grain boundary carbide networks.
\end{abstract}

KEYWORDS: sintered steels, ferrite, bainite, inverse bainite, martensite

\section{INTRODUCTION}

Microstructural development using phase transformation, i.e. atomic rearrangement causing changes of crystal structure, is scientifically and technologically important for $\mathrm{t}$ advanced high strength steels (AHSSs). Phase transformation products, phases or structures, are the main factors controlling mechanical properties of steel. Manufacturing technologies developed for tailoring microstructures according to phase transformations in AHSSs could be found in the literatures $[1,2]$. The common direction for developing AHSSs is toward high strength and high ductility $[3,4]$. In order to have both high strength and high ductility, the AHSSs' transformation products should have hard and soft phases because the high strength is obtained from hard phases and the high ductility from the soft phases. The common soft phases responsible for enhancing ductility in AHSSs are ferrite and retained austenite [5]. The combination of hard phase and retained austen- ite is the principal design for developing AHSSs, such as, transformation-induced plasticity (TRIP) steels [6], TRIP-aided martensite (TM) steels [7], TRIP-assisted multiphase steels [8], carbide-free bainite steels [9], nanostructured bainite [10] and quenched and partitioned ( $Q$ and $P$ ) steels [11]. The retained austenite plays an important role in enhancing formability of steels via TRIP effect by transforming to martensite during deformation [12]. Another function of retained austenite regarding deformation is dislocations absorption by retained austenite (DARA) effect [13, 14]. Thus, stability and deformation behaviors of retained austenite would affect mechanical properties of retained austenitecontaining steels.

In general, sintered steels have low ductility due to porosity [15]. The increase of ductility would be beneficial for the expansion of sintered steel applications. Although the porosity reduction in sintered steels can increase ductility, but the process would require additional materials, tools, 
Table 1 Nominal compositions of studied sintered steels.

\begin{tabular}{lcccccc}
\hline \multirow{2}{*}{ Steel } & SiC & \multicolumn{5}{c}{ Nominal composition (wt.\%) } \\
\cline { 3 - 7 } & (wt.\%) & C & Si & Mo & Mn & Fe \\
\hline 07Si03C & 1.0 & 0.3 & 0.7 & 0.50 & 0.15 & Balance \\
14Si06C & 2.0 & 0.6 & 1.4 & 0.49 & 0.15 & Balance \\
21Si09C & 3.0 & 0.9 & 2.1 & 0.49 & 0.15 & Balance \\
28Si12C & 4.0 & 1.2 & 2.8 & 0.48 & 0.14 & Balance \\
\hline
\end{tabular}

and processing steps, leading to increasing production cost. Recently, commercial pre-alloyed ironbased powders are available for sinter hardening (strengthening by martensite formation) purpose. However, to the best of authors' knowledge, the ambition for increasing sintered alloy ductility is limited. It is hypothesized in this study that if the TRIP effect is introduced to sintered steels, their ductility will be enhanced. To introduce TRIP effect to sintered steels, at least a method to produce retained austenite in sintered microstructure must be known. The manufacturing technologies for making wrought retained austenite-containing steels, as given in the literatures $[1,2]$ are perhaps not suitable for making sintered retained austenitecontaining steels because the latter steels contain porosity which is vulnerable to contamination entrapment caused by heat treatment media. It is indicative in the literatures $[10,11,16]$ that adding a suitable silicon content in a steel can prevent cementite precipitation, hence stabilize austenite due to carbon enrichment. Alloying a pre-alloyed iron-based powder with suitable silicon and carbon contents can be conducted by heating and sintering under a clean atmosphere (high vacuum).

In this study, methods to produce retained austenite in sintered steels were explored. Varied amounts of silicon carbide ( $\mathrm{SiC}$ ) powder were used as sources of silicon and carbon elements for alloying the pre-alloyed Fe-0.50Mo-0.15Mn powders. The focuses of the study were on the effects of varied silicon and carbon contents, inherited from varied $\mathrm{SiC}$ amounts, on phase transformations, which are deduced from relevant phase transformation products.

\section{MATERIALS AND METHODS}

\section{Materials preparation}

Sintered retained austenite-containing steels were prepared from mixtures of pre-alloyed Fe-0.5Mo$0.15 \mathrm{Mn}$ powder (ATOMET 4001 from Rio Tinto Metal Powders, Canada) and SiC powder (Sigma-
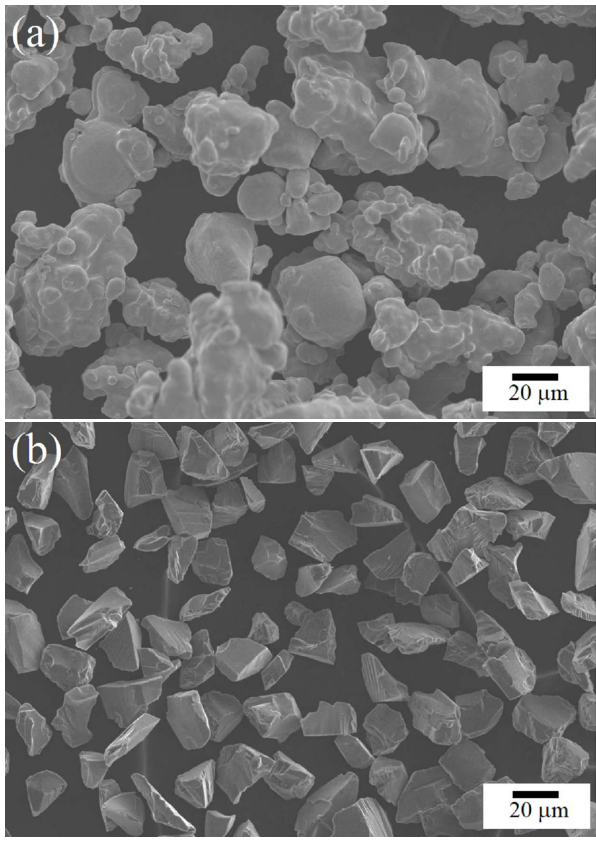

Fig. 1 Powder characteristics: (a) pre-alloyed Fe-0.50Mo$0.15 \mathrm{Mn}$ and (b) silicon carbide powders.

Aldrich chemistry, USA). The nominal compositions of sintered steels were given in Table 1 . The prealloyed Fe-0.5Mo-0.15Mn powder (Fig. 1(a)) had irregular shape and particle sizes of -100 mesh $(<150 \mu \mathrm{m})$. SiC powder (Fig. 1(b)) had facet shape and particle sizes of -400 mesh $(<38 \mu \mathrm{m})$. The $\mathrm{SiC}$ contents were varied from $1.0-4.0 \mathrm{wt} . \%$ with $1.0 \mathrm{wt} . \%$ increment. The powder mixtures were added with 1 wt.\% zinc stearate as a lubricant. The powder mixtures (plus lubricant) were then blended in a double cone tumbling mixer for 1 hour and subsequently compacted into tensile test bars, following MPIF Standard 10, with green density of $6.50 \pm 0.05 \mathrm{~g} / \mathrm{cm}^{3}$. Sintering of the powder compacts was conducted in a vacuum furnace (Schmetz, Germany) at $1250{ }^{\circ} \mathrm{C}$ for $45 \mathrm{~min}$. The sintered specimens were gradually cooled down by nitrogen gas with the rate of $3.6^{\circ} \mathrm{C} / \mathrm{s}$.

\section{Characterization}

Specimens for optical microscopy were prepared according to a standard procedure, including cutting, mounting, grinding (180 to 1200 grit silicon carbide papers), polishing (6, 3 and $1 \mu \mathrm{m}$ diamond pastes), and etching. The etchants employed were Groesbeck's reagent and $2 \% \mathrm{Nital}$ in ethanol. Groesbeck's reagent ( $100 \mathrm{ml}$ water, $4 \mathrm{~g} \mathrm{NaOH}, 4 \mathrm{~g} \mathrm{KMnO}_{4}$ ) was used for color tinting. Color etching was performed 
by immersing a specimen in the reagent at $60^{\circ} \mathrm{C}$ for $10 \mathrm{~min}$ (modified from the Vander Voort's [17]). Microstructural observation was conducted using Olympus STM7.

Specimens for scanning electron microscopy (SEM) were prepared according to the aforementioned standard procedure. The specimens for SEM observation were etched by $2 \%$ Nital. Microstructural observation was conducted using Hitachi SU5000.

Specimens for XRD were prepared by cutting, grinding, and polishing. XRD was performed using PANalytical X'pert pro with cobalt source (wavelength of $1.789 \AA$ ) and under conditions including step size of $0.2^{\circ}$, time of $0.5 \mathrm{~s} / \mathrm{step}$, and angle of $30-110^{\circ}$.

\section{Mechanical properties}

Microhardness and tensile tests were conducted. Microhardness test was carried out on 2\% Nitaletched specimens using $60 \mathrm{kgf}$ load (HRF), and the mean values were based on 3 tests at different areas. Tensile property of the sintered materials was carried out according to the ASTM E8M Standard with crosshead speed of $5 \mathrm{~mm} / \mathrm{min}$ at room temperature. Each sintered steel specimen was tested in triplicate using Instron Universal Instrument.

\section{RESULTS AND DISCUSSION}

\section{Microstructure}

\section{Sintered 07Si03C steel}

Microstructure of the sintered 07Si03C steel consisted of mainly coarse ferrite plates and mixtures of fine ferrite laths and particles (hereafter called 'FP mixtures') between the coarse ferrite plates (Fig. 2(a)). The morphologies of particles in FP mixtures varied as fine degenerate or discrete, acicular plate, and irregular plate shapes. The acicular and irregular plate shapes were suspected to be martensite/austenite (M/A) constituents, whereas the fine degenerate or discrete particles were suspected to be carbides.

The OM image of the sintered 07Si03C steel revealed that all particles in FP mixtures were colortinted by Groesbeck's reagent, and they appeared in brown; whereas coarse ferrite plates showed no response to Groesbeck's reagent (Fig. 2(b)). According to a literature [17], different carbides have different responses to Groesbeck's reagent. For example, $\mathrm{M}_{7} \mathrm{C}_{3}$ is tinted as faint, $\mathrm{M}_{6} \mathrm{C}$ as outlined/colored, and $\mathrm{M}_{2} \mathrm{C}$ as outlined. However, in the work of Colnet et al [18], MC carbides are not etched and
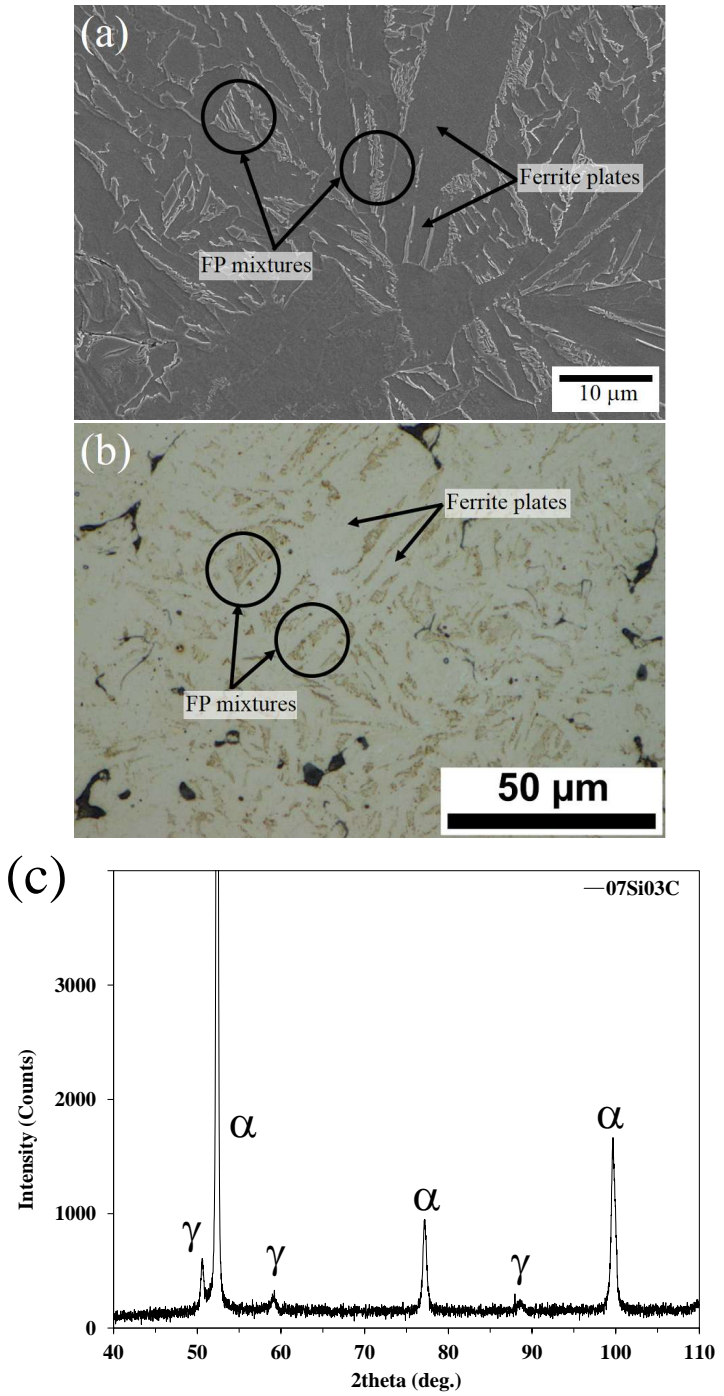

Fig. 2 Characterization of the sintered 07Si03C steel: (a) SEM image, (b) color-tinted OM image, and (c) XRD pattern.

appear in pink in the matrix, $\mathrm{M}_{2} \mathrm{C}$ in dark brown, and $\mathrm{M}_{7} \mathrm{C}_{3}-\mathrm{M}_{6} \mathrm{C}$ in blue or yellow. Both $\mathrm{M}_{6} \mathrm{C}$ and $\mathrm{M}_{7} \mathrm{C}_{3}$, which are always associated and have the same color, must be considered as a whole, when using optical microscopy. Therefore, it was possible that the particles between coarse ferrite plates tinted in brown could be the carbides in response to the Groesbeck's reagent.

To ensure whether the suspected particles in FP mixtures between coarse ferrite plates were carbides or not, the identification of phases in the sintered 07Si03C steel was conducted by XRD. The XRD result is shown in Fig. 2(c). No XRD peaks were cor- 
responding to carbides. According to XRD pattern interpretation, the retained austenite was the only minor phase in addition to the ferrite's major phase in this sintered steel. It was implied, therefore, that all particles in the FP mixtures between coarse ferrite plates were corresponding to the well-known M/A constituents [19]. The FP mixtures were then identified as fine ferrite and M/A mixtures.

Due to experimental results given above, the sintered 07Si03C steel microstructure had only two microstructural components: ferrite and M/A constituents. No carbides were observed in this steel. The ferrite plates were coarse and irregular. The M/A constituents in FP mixtures occupied ferrite plate boundaries. According to the classification of bainite given by Zajac et al [20], Caballero et al [21], and Müller et al [22], the microstructure consisting of ferrite and M/A constituents could be classified into granular bainite, degenerate upper bainite, or degenerate lower bainite. The characteristics of granular bainite consisted of irregular ferrite with carbon-rich second phases distributed between these irregular grains. This bainite classification suited the microstructural feature consisting of ferrite and $\mathrm{M} / \mathrm{A}$ constituents observed in the sintered 07Si03C steel.

These characteristics suggested that the sintered 07Si03C steel microstructure could be termed as granular bainite [23]. The granular bainite was observed in some steels produced via continuous cooling [24, 25] and one via hot rolling [26]. The microstructure given in Fig. 2(a) was similar to that of a TB steel austempered at $475^{\circ} \mathrm{C}$ for $200 \mathrm{~s}$ [27].

Phase transformations in the sintered 07Si03C steel under continuous cooling rate of $3.6^{\circ} \mathrm{C} / \mathrm{s}$ included Widmanstätten ferrite transformation at higher temperatures followed by the decomposition of the remaining austenite to granular bainite structure at lower temperatures. The martensite in $\mathrm{M} / \mathrm{A}$ constituents of granular bainite was formed at temperatures below martensite start temperature. This was attributed to the stability of untransformed austenite, resulting from carbon enrichment by carbon diffusion from transformed ferrite laths/plates and carbide precipitation retardation by dissolved silicon in austenite $[10,11,16]$. Some portions of austenite transformed to martensite, and the rest remained as retained austenite below martensite start temperature. It could be seen later that the $\mathrm{M} / \mathrm{A}$ constituents increaseed with increasing added SiC content.
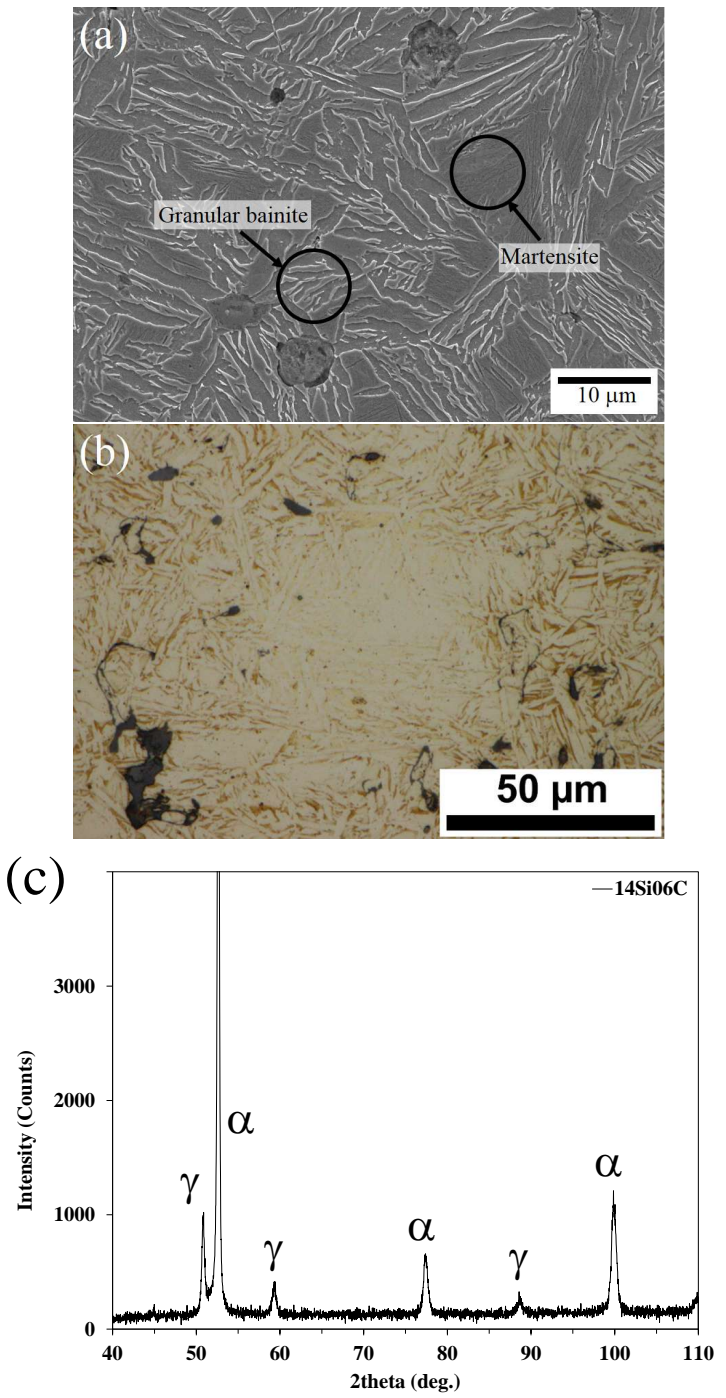

Fig. 3 Characterization of the sintered 14Si06C steel: (a) SEM image, (b) color-tinted OM image, and (c) XRD pattern.

\section{Sintered 14Si06C steel}

Microstructure of the sintered 14 Si06C steel consisted of mixtures of granular bainite and lath martensite (Fig. 3(a)). The color-tinting revealed that the islands on ferrite lath boundaries in granular bainite structure reacted with Groesbeck's reagent and appeared in brown (Fig. 3(b)). In the middle of Fig. 3(b), light brown films highlighted the boundaries of lath structures (in white) with no responses to Groesbeck's reagent. This light-tinted area was possibly corresponding to lath martensite. No response of martensite to Groesbeck's reagent was observed in the sintered high-carbon steels 
such as sintered $21 \mathrm{Si09C}$ and sintered 28Si12C steels. XRD peaks corresponding to carbides were not found in the sintered 14Si06C steel (Fig. 3(c)). According to XRD pattern indexing, only ferrite and austenite phases could be identified in the sintered 14Si06C steel.

Steels consisting of bainite and martensite components were previously reported in the literatures $[28,29]$. In $\mathrm{Cr}$-free and $\mathrm{Cr}$-added carbide-free steels, austempered at 430 to $450^{\circ} \mathrm{C}$, showed the coexistence of bainite and martensite [30]. Similarly, bainite and martensite were observed to coexist in carbide-free bainite steels with different $\mathrm{Si}$ contents [31].

Phase transformation series in the sintered 14Si06C steel under continuous cooling rate of $3.6^{\circ} \mathrm{C} / \mathrm{s}$ starts with the decomposition of austenite to granular bainite structure followed by martensite transformation at lower temperatures.

\section{Sintered 21Si09C steel}

The microstructural components of sintered 21Si09C steel were martensite with some bainitic ferrite laths distributing within matensitic matrix (Fig. 4(a)). The color-etched OM image showed brown films on bainitic ferrite lath boundaries, whereas the martensite matrix showed no response to color etching (Fig. 4(b)). The brown films represented retained austenite films on bainitic ferrite lath boundaries. In some areas, there were transformation product aggregates (TPAs) embedded in martensite matrix. The TPAs consisted of pearlite, inverse bainite, and bainitic ferrite laths (Fig. 4(c)). Color tinting could fairly highlight TPAs (Fig. 4(d)). The pearlite component of TPAs showed the least response to color tinting. Clear distinction between pearlite and inverse bainite is given in Fig. 4(e). XRD pattern of the sintered 21Si09C steel showed peaks corresponding to martensite and austenite phases (Fig. 4(f)). The overlapping between the austenite (111) and the martensite (110) peaks resulted in shoulder formation on the left-hand side of the martensite (110) peak. XRD peaks corresponding to carbides were hardly observed due to low volume fraction of pearlite and inverse bainite.

The bainitic ferrite laths embedded in martensitic matrix (Fig. 4(a)) had two morphologies, one with high aspect ratio and smooth surfaces and the other with lower aspect ratio and wavy surfaces. The bainitic ferrite laths in TPAs (Fig. 4(c)) had high aspect ratio and smooth surfaces. They nucleated at a prior austenite grain boundary and grew continuously to the interface of inverse bainite without the sign of sympathetic nucleation, i.e. the nucleation of new ferrite laths at boundaries of the pre-existing ones.

A large portion of this alloy microstructure was occupied by martensitic matrix embedded with some bainitic ferrite laths. This suggested that higher silicon and carbon contents stabilized austenite at lower temperatures, e.g., below martensite forming temperature. At low temperatures, bainitic ferrite laths and martensite were formed. The other evidence supporting austenite stabilization by high silicon and carbon contents was the increase of retained austenite XRD peaks compared with those of martensite (Fig. 4(f)).

The microstructure of the sintered 21Si09C steel (Fig. 4(a)) was similar to those of steels austempered at low temperatures for short periods [32-34]. The volume fraction of bainitic ferrite plates formed depended on the alloy's composition [30], austempering temperature, and time [35]. The bainitic ferrite plate quantity increaseed with increasing isothermal holding time.

The microstructural similarity of the sintered 21Si09C steel and the austempered steels mentioned above implied that phase transformation in the former steel occured at a low temperature. The low volume fraction of bainitic ferrite plates also indicateed that bainite transformation kinetics in the sintered 21Si09C steel was too slow to complete under the continuous cooling rate employed in this study. The sluggish bainite transformation was superseded by martensite transformation in untransformed austenite regions. This sluggish bainite transformation at low temperatures was previously reported in a high-carbon-high-silicon steels [36].

\section{Sintered 28Si12C steel}

The sintered 28Si12C steel exhibited the most complex microstructure of all studied sintered steels. It consisted of coarse grain boundary (GB) carbide particles, bainitic ferrite laths, martensite, and pearlite-like structure (Fig. 5(a,b)). Fig. 5(c) shows the GB carbide particles tinted in dark brown, the retained austenite on the edges of bainitic ferrite laths and between martensite laths/plates tinted in brown; while the bainitic ferrite laths, the martensite, and the pearlite-like structure not tinted. The XRD pattern (Fig. 5(d)) showed strong peaks of austenite and martensite.

The presences of pearlite-like structure consist- 


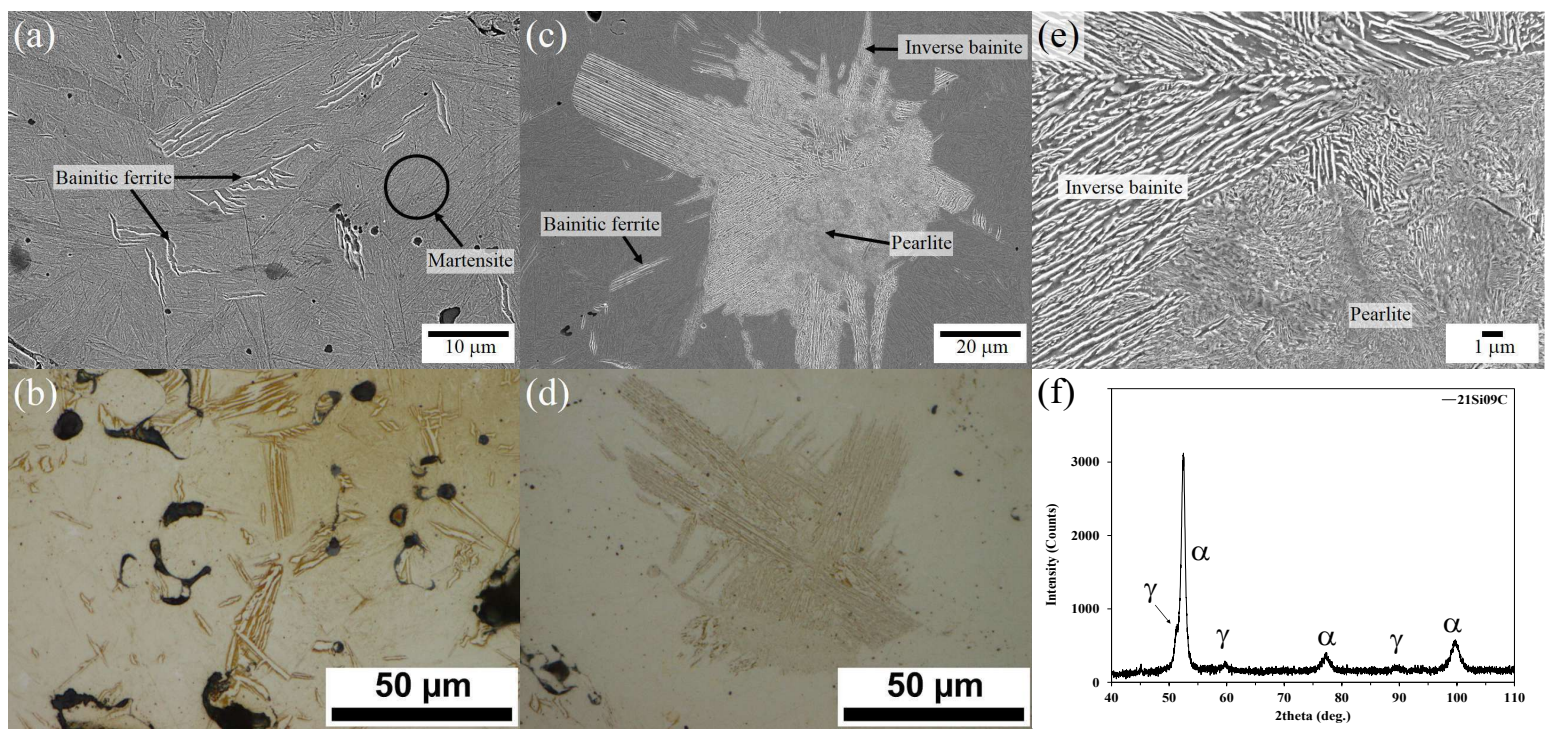

Fig. 4 Characterization of the sintered 21Si09C steel: (a,c,e) SEM images, (b,d) color-tinted OM images, and (f) XRD pattern.
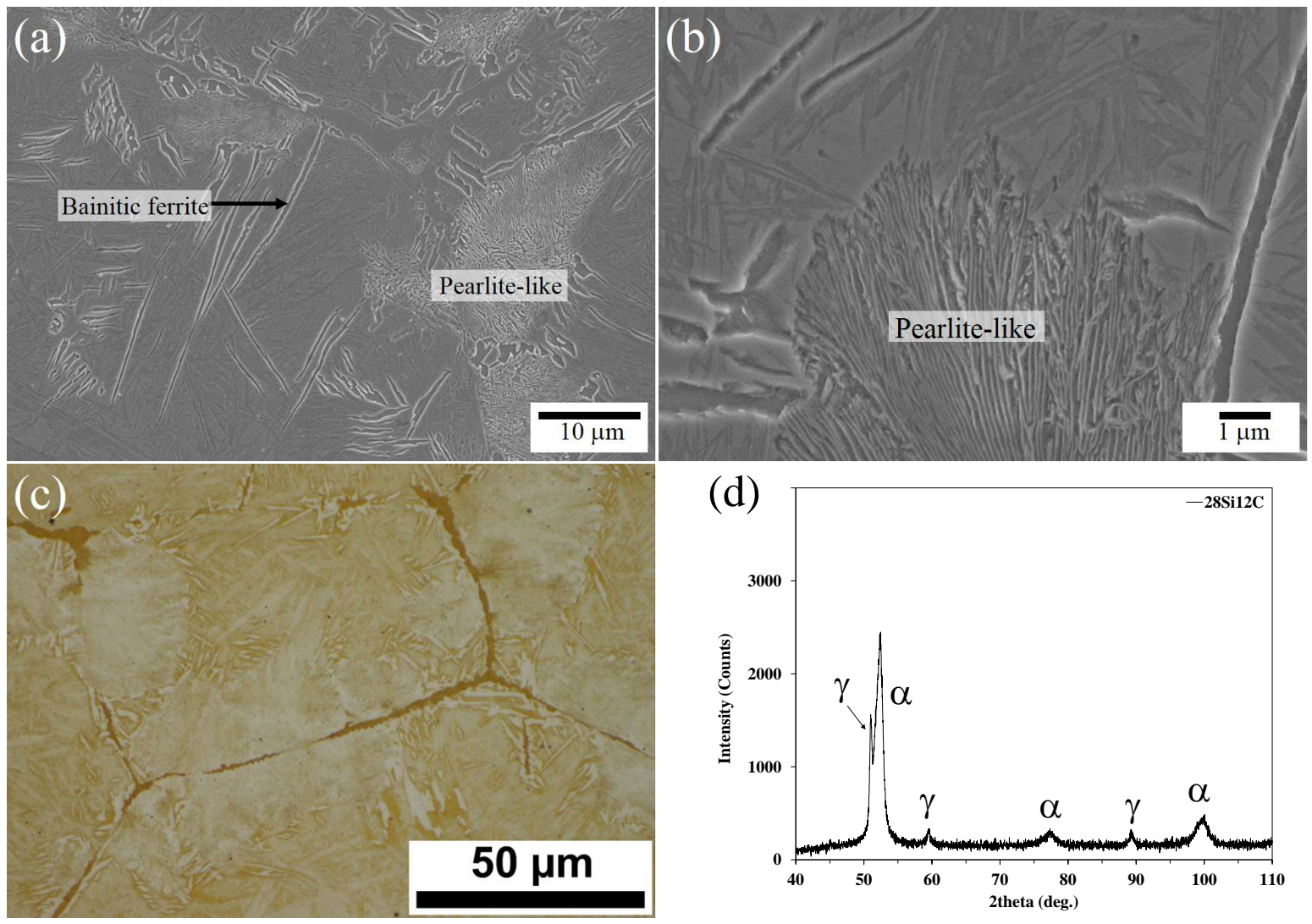

Fig. 5 Characterization of the sintered 28Si12C steel: (a,b) SEM images, (c) color-tinted OM image, and (d) XRD pattern. 
ing of ferrite and carbide lamellae (Fig. 5(b)) and coarse GB carbide particles (Fig. 5(c)) indicated that diffusional phase transformations occured before martensite phase transformation. Although the sintered 28Si12C steel had high silicon and high carbon contents and was processed under the cooling rate of $3.6^{\circ} \mathrm{C} / \mathrm{s}$, diffusional phase transformations still occurred. High silicon contents cannot prevent carbide precipitation in some cases. One recent literature mentioned that despite the addition of silicon, the carbide precipitation still occurs during partitioning [37].

In previous work, the microstructure consisting of pearlite, bainite, martensite, and retained austenite was reported in high carbon Si-Mn-Cr steels [38]. While the microstructure consisting of pearlite and $\mathrm{M} / \mathrm{A}$ constituents embedded in tempered martensite was observed in the Q\&P 650 [39].

\section{Mechanical properties}

Mechanical properties of studied sintered steels were shown in Fig. 6. The values of ultimate tensile strength and yield strength increased with increasing added $\mathrm{SiC}$ contents up to $3 \mathrm{wt} . \%$. The strength values dropped when $4 \mathrm{wt} . \% \mathrm{SiC}$ was added. Moreover, the hardness value increased, whereas the elongation value decreased, with increasing $\mathrm{SiC}$ contents.

The increases of strength and hardness of sintered steels were attributed to parameters, including morphology and sizes of ferrite and martensite fraction. The effect of ferrite plate size on the strength and the hardness was clearly seen when microstructures of the sintered 07Si03C steel (Fig. 2(a)) and the sintered 14Si06C steel (Fig. 3(a)) were compared. The effect of martensite fraction on strength and hardness started to show in the sintered 14Si06C steel. In the sintered 21Si09C and 28Si12C steels, martensite was the dominant microstructural component. Thus, the increase of hardness in these two sintered steels depended on the martensite fraction. The inferior tensile strength of the sintered 28Si12C steel was due to the grain boundary carbide networks (Fig. 5(c)).

All the XRD patterns mentioned above indicated that retained austenite fraction increased with increasing added SiC contents. However, elongation value decreased with increasing added $\mathrm{SiC}$ contents. This indicates that the volume fraction of retained austenite is not the only factor controlling ductility. In general ductility enhancement is obtained by the austenite to martensite transformation during deformation, known as transformation induced
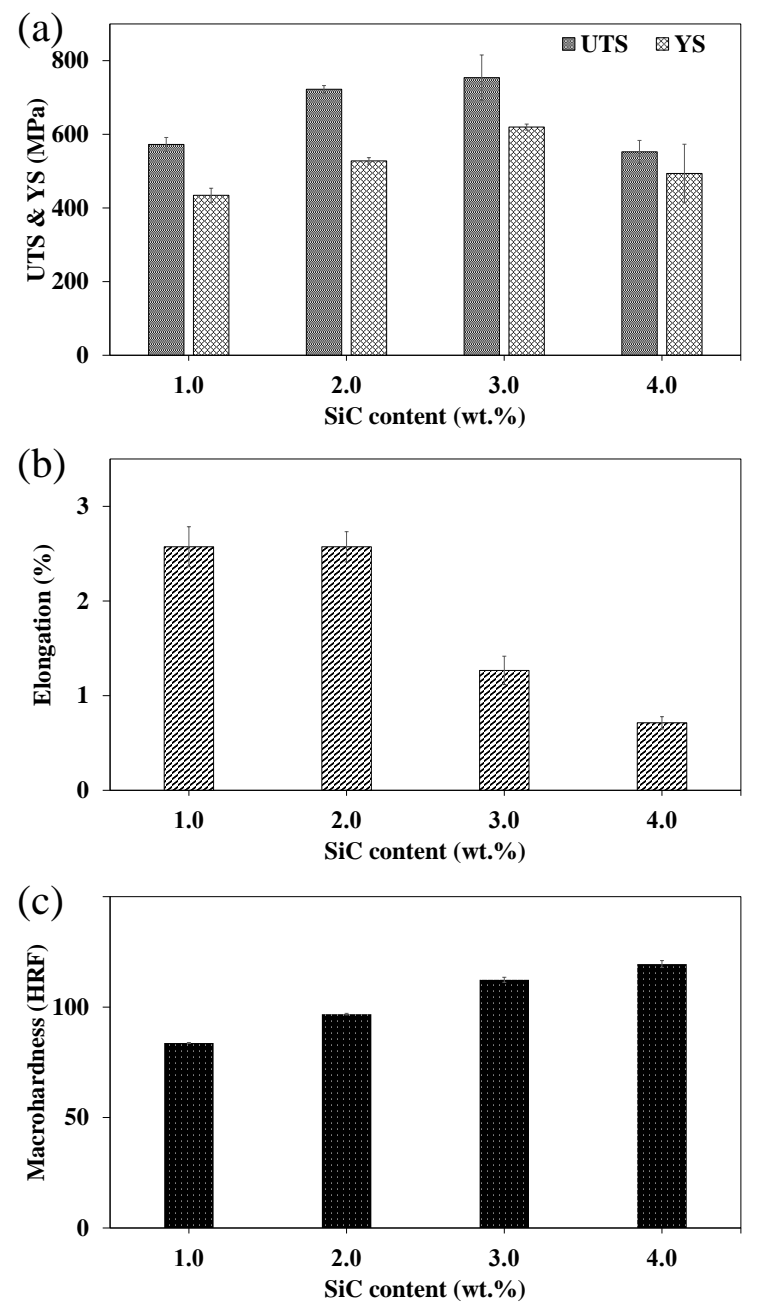

Fig. 6 Mechanical properties of sintered steels: (a) ultimate tensile strength (UTS) and yield strength (YS), (b) elongation, and (c) microhardness.

plasticity (TRIP) effect. TRIP effect is controlled by retained austenite parameters. The important retained austenite parameter related to TRIP effect is mechanical stability. However, it was mentioned in the past study that too stable austenite was no guarantee for better results [40]. To understand the decrease of ductility with increasing retained austenite fraction, further investigation on mechanical stability of retained austenite in these sintered steels is underway.

\section{CONCLUSION}

Microstructures of sintered steels changed in accordance to added $\mathrm{SiC}$ contents. In a low silicon carbide-added steel, the microstructure consisted of ferrite plates and martensite/austenite islands on 
ferrite plate boundaries. In a high silicon carbideadded steel, small amounts of pearlite, inverse bainite, and bainitic ferrite were observed within martensite matrix. However, in the sintered steel added with 4 wt.\% SiC, grain boundary carbide networks formed and led to tensile strength deterioration. Strength and hardness of sintered steels depended on morphology and sizes of ferrite and martensite fraction. Although the retained austenite fraction increased with increasing added $\mathrm{SiC}$ content, the sintered steels did not gain enhanced ductility due to TRIP effect.

Acknowledgements: The first author is grateful for financial support from TGIST scholarship of NSTDA (TG33-26-60-016D). This work is financially supported via the project 'Design and manufacturing of replacement parts for railway applications (P1951261)' under National Science and Technology Development Agency (NSTDA), Pathum Thani, Thailand. Technical supports are obtained from National Metal and Materials Technology Center (MTEC), Pathum Thani, Thailand. The courtesy of ATMET4001 powder by P.S. Steel Co., Ltd., the metal powder distributor of Rio Tinto Metal Powders of Canada is also grateful.

\section{REFERENCES}

1. Kuziak R, Kawalla R, Waengler S (2008) Advanced high strength steels for automotive industry. Arch Civ Mech Eng 8, 103-117.

2. Schmitt JH, Iung $\mathrm{T}$ (2018) New developments of advanced high-strength steels for automotive applications. C R Phys 19, 641-656.

3. Zhao J, Jiang Z (2018) Thermomechanical processing of advanced high strength steels. Prog Mater Sci 94, 174-242.

4. Jha G, Das S, Sinha S, Lodh A, Haldar A (2013) Design and development of precipitate strengthened advanced high strength steel for automotive application. Mater Sci Eng A 561, 394-402.

5. Dai Z, Chen H, Ding R, Lu Q, Zhang C, Yang Z, van der Zwaag S (2021) Fundamentals and application of solid-state phase transformations for advanced high strength steels containing metastable retained austenite. Mater Sci Eng R Rep 143, ID 100590.

6. De Cooman BC (2004) Structure-properties relationship in TRIP steels containing carbide-free bainite. Curr Opin Solid State Mater Sci 8, 285-303.

7. Sugimoto K, Srivastava AK (2015) Microstructure and mechanical properties of a TRIP-aided martensitic steel. Metallogr Microstruct Anal 4, 344-354.

8. Jacques PJ, Furnemont Q, Godet S, Pardoen T, Conlon KT, Delannay F (2006) Micromechanical characterisation of TRIP-assisted multiphase steels by in situ neutron diffraction. Philos Mag 86, 2371-2392.
9. Khare S, Lee K, Bhadeshia HKDH (2010) Carbidefree bainite: Compromise between rate of transformation and properties. Metall Mater Trans A 41, 922-928.

10. Bhadeshia HKDH (2009) Nanostructured bainite. Proc Math Phys Eng Sci 466, 3-18.

11. Speer JG, Assunção FCR, Matlock DK, Edmonds DV (2005) The "quenching and partitioning" process: background and recent progress. Mater Res $\mathbf{8}$, 417-423.

12. Hanzaki AZ, Hodgson PD, Yue S (1995) Hot deformation characteristics of Si-Mn TRIP steels with and without $\mathrm{Nb}$ microalloy additions. ISIJ Int $\mathbf{3 5}$, 324-331.

13. Zhang K, Zhang M, Guo Z, Chen N, Rong Y (2011) A new effect of retained austenite on ductility enhancement in high-strength quenching-partitioningtempering martensitic steel. Mater Sci Eng A 528, 8486-8491.

14. Wang Y, Zhang K, Guo Z, Chen N, Rong Y (2012) A new effect of retained austenite on ductility enhancement in high strength bainitic steel. Mater Sci Eng A 552, 288-294.

15. Chawla N, Deng X (2005) Microstructure and mechanical behavior of porous sintered steels. Mater Sci Eng A 390, 98-112.

16. Kozeschnik E, Bhadeshia HKDH (2008) Influence of silicon on cementite precipitation in steels. Mater Sci Technol 24, 343-347.

17. Vander Voort GF, Manilova EP, Michael JR, Lucas GM (2004) Study of selective etching of carbides in steel. Microsc Microanal 10, 76-77.

18. Colnet LD, Pirard E, Tchuindjang JT, Beckers JL, Gfhiri R, Boeraeve P, Cescotto S (2001) Quantitative description of $\mathrm{MC}, \mathrm{M}_{2} \mathrm{C}, \mathrm{M}_{6} \mathrm{C}$ and $\mathrm{M}_{7} \mathrm{C}_{3}$ carbides in high speed steel rolls. In: Proceedings of the MSMF-3 International Conference, Czech Republic, pp 710-717.

19. Biss V, Cryderman RL (1971) Martensite and retained austenite in hot-rolled, low-carbon bainitic steels. Metall Mater Trans B 2, 2267-2276.

20. Zajac S, Schwinn V, Tacke KH (2005) Characterisation and quantification of complex bainitic microstructures in high and ultra-high strength linepipe steels. Mater Sci Forum 500-501, 387-394.

21. Caballero FG, Capdevila C, Chao J, Cornide J, Mateo CG (2012) The microstructure of continuously cooled tough bainitic steels. Mater Sci Technol 28, 95-102.

22. Müller M, Britz D, Ulrich L, Staudt T, Mücklich F (2020) Classification of bainitic structures using textural parameters and machine learning techniques. Metals 10, ID 630.

23. Josefsson B, Andrén HO (1988) Microstructure of granular bainite. J Phys Colloq 49, C6-293-C6-298.

24. Wang JP, Yang ZG, Bai BZ, Fang HS (2004) Grain refinement and microstructural evolution of grain 
boundary allotriomorphic ferrite/granular bainite steel after prior austenite deformation. Mater Sci Eng A 369, 112-118.

25. Jia SJ, Li B, Liu QY, Ren Y, Zhang S, Gao H (2020) Effects of continuous cooling rate on morphology of granular bainite in pipeline steels. J Iron Steel Res Int 27, 681-690.

26. Tian Y, Tan Z, Li J, Gao B, Zhang M, Bai B (2020) Ultrahigh toughness of a 20Mn2SiCrNi bainitic steel. Metals 10, ID 19.

27. Sugimoto K, Sakaguchi J, Iida T, Kashima T (2000) Stretch-flangeability of a high-strength TRIP type bainitic sheet steel. ISIJ Int 40, 920-926.

28. Yu Y, Gu JL, Bai BZ, Liu YB, Li SX (2009) Very high cycle fatigue mechanism of carbide-free bainite/martensite steel micro-alloyed with Nb. Mater Sci Eng A 527, 212-217.

29. Gao G, Zhang H, Tan Z, Liu W, Bai B (2013) A carbidefree bainite/martensite/austenite triplex steel with enhanced mechanical properties treated by a novel quenching-partitioning-tempering process. Mater Sci Eng A 559, 165-169.

30. Zhou M, Xu G, Tian J, Hu H, Yuan Q (2017) Bainitic transformation and properties of low carbon carbidefree bainitic steels with Cr addition. Metals 7, ID 263.

31. Tian J, Xu G, Jiang Z, Wan X, Hu H, Yuan Q (2019) Transformation behavior and properties of carbide free bainite steels with different Si contents. Steel Res Int 90, ID 1800474.
32. Caballero FG, Bhadeshia HKDH, Mawella KJA, Jones DG, Brown P (2002) Very strong low temperature bainite. Mater Sci Technol 18, 279-284.

33. Hofer C, Leitner H, Winkelhofer F, Clemens H, Primig $S$ (2015) Structural characterization of "carbidefree" bainite in a Fe-0.2C-1.5Si-2.5Mn steel. Mater Charact 102, 85-91.

34. Toji Y, Matsuda H, Raabe D (2016) Effect of Si on the acceleration of bainite transformation by preexisting martensite. Acta Mater 116, 250-262.

35. Dalwatkar R, Prabhu N, Singh RKP (2018) Effect of austempering temperature and time on mechanical properties of SAE 9260 steel. AIP Conf Proc 1957, ID 040001.

36. Caballero FG, Mateo CG, Bhadeshia HDKH (2003) Low temperature bainite. J Phys IV 112, 285-288.

37. Kim B, Sietsma J, Santofimia MJ (2017) The role of silicon in carbon partitioning processes in martensite/austenite microstructures. Mater Des 127, 336-345.

38. Santos DB, Barbosa R, Oliveira PP, Pereloma EV (2009) Mechanical behavior and microstructure of high carbon Si-Mn-Cr steel with Trip effect. ISIJ Int 49, 1592-1600.

39. Masoumi M, Echeverri EAA, Tschiptschin AP, Goldenstein $H$ (2019) Improvement of wear resistance in a pearlitic rail steel via quenching and partitioning processing. Sci Rep 9, ID 7454.

40. García-Mateo C, Caballero FG (2005) The role of retained austenite on tensile properties of steels with bainitic microstructures. Mater Trans 46, 1839-1846. 